1909.

\section{THE MODE OF ACTION OF THE BIOLOGICAL FILTER,}

By T. CARNWATH, B.A., M.D., D.P.H. Camb., Assistant to the Medical Officer of Health, Manchester.

THE origin of the modern biological filter may be traced to Frankland's experiments in 1870 .

Its evolution I would briefly sketch as follows :-

In the first place Frankland showed that the old method of continuous filtration or irrigation was wrong in principle in that no time was allowed for aeration and regeneration. He proved that if the maximum effect is to be obtained from the purifying agencies at work in the soil, a "breathing" or "resting" interval must be allowed between the floodings.

Then came the experiments of Clarke and others for the Massachusetts Board of Health. $\dagger$ They showed that attention must be paid not only to the breathing interval but also to the amount of sewage applied at each flooding. This, they say, should never exceed the water capacity 1 of the filter: as a rule $\frac{1}{4}$ to $\frac{1}{8}$ of this amount is sufficient.

But the water capacity varies with the coarseness or "effective size" $\$$ of a material (the "uniformity co-efficient" remaining constant). The coarser, that is, the material the smaller its water capacity, and vice versa. It follows, therefore, that a filter composed of fine materials will be able to deal with a larger quantity of sewage at one time than a coarse filter, but it has the disadvantage that it requires a much longer resting interval for regeneration, and in practice it is found that this latter more than counterbalances the advantage it possesses in the matter of capacity.

These relations may be tabulated thus :-

\begin{tabular}{ccccc} 
& \multicolumn{3}{c}{ TaBLE 1.} & \\
Effective size. & & Dose. & \multicolumn{2}{c}{ Resting interval. } \\
Small & $\ldots$ & Large & $\ldots$ & Long \\
Large & $\ldots$ & Sinall & $\ldots$ & Short
\end{tabular}

And so we may trace the steps of the transition from the "intermittent filter" of Frankland with its fine materials (clay, sand, etc.), large dose and long resting interval to the "intermittent percolating filter" of to-day, with its coarse materials (clinker, broken brick, etc.), small dose and short resting interval :-

* Report of Rivers Pollution Commission, 1868 .

+ Annual Reports, State Board of Health. $\ddagger$ Annual Report, I $8 \mathrm{gI}$, p. 435 .

$\$$ Massachusetts Report, I895, et seq.; also Kammann u Carnevath.
Table 2.

Continuous irrigation.

Intermittent irrigation or filtration

(clay, sand, etc.)

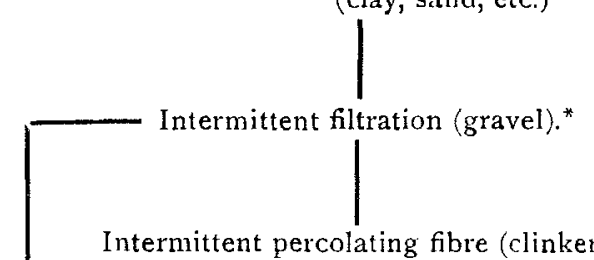

Intermittent percolating fibre (clinker, etc),

Contact Bed.

(Dibdin.)

For the purpose of this paper one might describe the contact bed as the result of an ingenious (and successful) attempt to rectify the (theoretical) mistake of applying too large a dose at one time.

From the above sketch we see that the different forms of filter met with at the present time are the result merely of variations in the empiric application of one and the same principle, so that a theory or explanation which holds for one will hold for all.

One of the most obvious effects of the filtration of sewage is the rapid production of nitrates. The discovery of a bacterial cause $f$ for this led gradually to the assumptionprobably in the main correct-that all the other changes are also the result of bacterial action. The simplicity of this explanation has made it popular. Few stop to enquire hore the bacteria act-what their exact rôle is in the process of purification-and as a consequence very hazy conceptions prevail on the subject. As an example, I quote the following passage: "The essential conditions (for efficient purification) are very slow motion of very thin films of liquid over the surface of particles having spaces between sufficient to allow air to be continually in contact with the films of liquid. With these conditions it is essential that certain bacteria should be present to aid in the process of nitrification. These we have found come in the sewage at all times of the year, and the conditions just mentioned appear to be most favourable for their efficient action, and at the same time most destructive to them and to all kinds of bacteria which are in the sewage."

From this it is difficult to form a clear conception of how the bacteria are supposed to act :

*Annual Report, Massachusetts Board of Health, 7890, p. 34 . + Schloesing 6 M Mnntz-Comptes rendus 1877 , pp. 84 , 301; Warring-
ton-Journal of Society of Arts, I882. 
whether they do their work as they ride with the stream, or whether, taking up their abode in the nooks and crannies of the filter they attack and seize on the organic matter, as it trickles past.

Dibdin, than whom no one has a wider experience or more intimate knowledge of this subject, still apparently inclines to the view that the* purification effected in a contact filter is due to the direct action of the bacteria and to fermentative and oxidative changes occurring in the filter during the standing-full period. The intervals between the fillings are for the object of giving the micro-organisms a rest and air. "The contact of the micro-organisms with the effluent to be purified must be effected by leaving such effluent to rest in the filter for a greater or less time according to the degree of purification required, the process being analogous to that of fermentation." " After such quantity of effluent has been dealt with the micro-organisms must be supplied with air."

"The filter must stand empty for an hour or more previous to another filling, and a long period of aeration, say 24 hours, must be allowed every 7 to 8 days. The life of a cokebreeze filter worked in this way is practically without limit."

If the bacterial theory as so conceived be strictly correct, then one may assume, from a knowledge of the course of bacterial fermentations, that the curve of purification will be gradual, rising slowly at first, then more quickly with increase in the number and activity of the bacteria, until finally a maximum is reached, which will be determined by the rate of accumulation of toxic and other products.

But, as a matter of fact, the exact opposite is the case. It has been shownt that the maximum effect in the case of a contact bed occurs during the first five to ten minutes, and that subsequent improvement in the condition of the effluent is slow and comparatively slight. This is especially so in a fine-grained filter, where intimate contact is at once secured, and it obtains not only for sewage containing much matter in suspension, but also for sewage which has been carefully freed from such, as well as for solutions of albumen, peptone, etc.,

* "Purification of Sewage and Water," p. 64 .

+ Dunbar.-Vierteljahrschrift f. gerioht., Mediz. u off Sanitïtswesen. 3 Folge, xix. Suppl. Heft., p. I78. cf. Barwise-" Purification of Sewage," p. 127. As pointed out by Barwise, "prolonging the period of contact is p. 127. As pointed out by Barwise, "prolonging the period of contact is mately mixed," and also in allowing time for the disintegration of any soluble non-absorbable carbohydrates which may be present and thei oxidation at the expense of nitrates, etc., which have been formed during previous resting intervals. where mechanical influences may be considered negligible.

As it is difficult to believe that any appreciable effect can be caused by bacteria or their enzymes in such a short space of time as five to ten minutes, we may conclude that, at any rate, the primary purification effect is due to some other force than a pure bacterial.

In support of this view it has been further demonstrated* that the purifying power of a filter does not disappear simultaneously with a cessation in the activity of the bacteria. Thus when a filter is chloroformed or when a strong antiseptic, such as corrosive sublimate, is added in sufficient quantity to inhibit bacterial or ferment action, the filter will still continue to purify the sewage for several fillings almost as perfectly as before. Soon, it is true, the effluents deteriorate until finally they appear at the outlet unchanged, and differing in no way from crude sewage.

As a result of these and other observations, Dunbar has advanced $\dagger$ the view that purification-or the removal of the putrescible organic matter-is primarily due not to the direct action of the bacteria, but to a process of absorption, the continuance of which, however, is dependent on the activity of micro-organisms in the presence of oxygen.

To attempt a precise definition of the term absorption as here used is difficult. Dunbar says: "When we speak of absorptive power and of absorptive activity, it must be understood that a satisfactory scientific explanation of the processes indicated thereby has not yet been found. What we do know is that when certain solutions," e.g., colloid solutions, " are brought into contact with garden earth, animal charcoal or other suitable material a removal or separation of the substance in solution occurs; in other words, a result is obtained which is not to be explained by ordinary chemical or mechanical principles." According to chemico-physical nomenclature the term "adsorption" should perhaps be applied to this phenomenon. Lachaud $\ddagger$ defines "adsorption" as "condensation of the substance in solution on the surface of the adsorbing medium by reason of a hypothetical attraction or mechanical affinity existing between the two."

In reference to sewage purification, however, it is perhaps preferable to use the term

* Dunbar $n$ Thumm, Baitrag z. derz. Stande d. Abwasserreinigungsfrage, C. IV.

+1.c.; also Gesundheits-ingenieur, I903, Nos. 33, 44 .

I Comptes rendus 122,1896, S. 1328 . 
1909.

"absorption," following here the lead of the agricultural chemists, by whom the word has long been applied to those processes by which water is freed from its organic impurities in its passage through soil, and thus indicating by this new application of the term the continuity of principle which exists between the old "irrigation" and the modern "filtration" systems.

Crude domestic sewage is water containing various organic and inorganic substances partly in solution and partly in suspension. When sewage is brought on to a ripe filter a more or less complete elimination of these substances is effected.

The suspended matters are removed mechanically.

Of the dissolved inorganic substances some, such as the chloride, pass through unchanged; others, e.g., sulphuretted hydrogen and possibly ammonia, are retained, probably as the result of a chemical combination with some constituent of the filter. Thus sulphuretted hydrogen is often retained as sulphide of iron. Others again may disappear as the result of direct oxidation by the adsorbed oxygen. The importance of this factor in purification does not appear to be sufficiently recognized. Under laboratory conditions, examples of its activity are furnished by solutions of Dimethylaniline* (colourless) and of calcium hypochlorite, + both of which, when brought into contact with fragments from a ripe filter, are very quickly oxidised, the former to methyl violet-a change which ordinarily requires heat and the addition of some strong oxidising agent-and the latter to chlorate. $\neq$

But it is not as a rule the presence of any inorganic substance which renders the purification of sewage necessary. It is rather the complex putrescible albumenoid matters on the removal of which we lay the chief stress. These are mainly colloidal. Their elimination in the biological filter is the work of a few minutes. It seems, therefore, reasonable to conclude that the force-the primary force effecting their separation and retention-is not a bacterial, but a chemico-physical-absorption.

But the absorptive power of a filter is limited. According to Lachaud, absorption will continue until a condition of equilibrium is established between the colloid in solution and that retained on the absorbing medium. So in a

* Lazbbert, quoted by Dunbar, loc cit.

+ Dunbar il Korn, Gesundheits-ingenieur, 1904, No. 2.

\$ This fact has suggested the use of chloride of lime as a disinfectant in cases where the sewage is to be subsequently treated by filtration. (Dunbar.) filter: once this condition of equilibrium is established once the absorptive power is exhausted, no further purification or elimination of colloids can take place. The filter must first undergo regeneration (resting interval).

The factors necessary for regeneration are micro-organisms and an abundant supply of oxygen. Through the agency of the microorganisms and their enzymes the absorbed matters are broken down and the products then immediately oxidised partly by the direct action of the oxygen (see above) and partly by the action of nitrifying and other bacteria.

By this conversion of the colloidal matters into substances which are either not absorbable at all (e.g., nitrates) or less easily absorbable than the mother-substance a regeneration of the filter is brought about--a disturbance of equilibrium is caused which at the next filling results in the elimination of the products of " mineralisation," and their place being taken by fresh colloid.

From the above it is seen that the "absorption" theory differs from the "bacterial," in that it divides the process of purification into two distinct stages : first, a stage of absorption or of separation and retention of the dissolved impurities; and, secondly, a bacterio-chemical stage of regeneration (resting interval), during which the absorbed matters are broken down and mineralised. Practically, it is impossible to draw a line of demarcation between the two stages. They merge into one another, and in a percolating filter absorption and regeneration may proceed side by side.

It differs, further, in that it postulates the presence of an absorbent. Now, as almost any material* may be used for the making of a filter, it follows that the absorbent is not necessarily something originally present in the filter. It is rather a product of the process of ripening. If a ripe filter be examined, the fragments composing it will be found to be covered with a brownish-black deposit, which, when examined microscopically, is seen to consist largely of "worked over" animal and vegetable débris, and when tested with colloid solutions is found to have absorbent powers almost.equal to those of animal charcoal. It is no doubt the formation and accumulation of this materialthis residue of previously absorbed organic matter-which chiefly constitutes what we know as the process of ripening.

Here lies the weakness as well as the strength

* Cloyes and Houston, Treatment of London Sewage, p. 15 .

+ Clowes and Houston,-l.c. See also Massachusetts Reports, rgat and previous years. 
of the biological filter, in that the accumulation of this deposit does not cease when a bed is ripe. It continues to form as before, and, though much of it is carried away in the effluent, still it is almost certain that sufficient will remain to cause ultimately blocking of the filter. In practice, of course, other factors influence the rate at which blocking occurscharacter of the sewage, durability of the filtering materials, manner of handling the bed, etc. But even with a perfectly sedimented domestic sewage and "ideal" filtering materials with proper management, it is doubtful whether the life of a filter can be regarded as unlimited.

It is well to emphasise the fact, * however, that the deposit which forms in a well-managed filter is very different from the sludge which is

F IG. I.

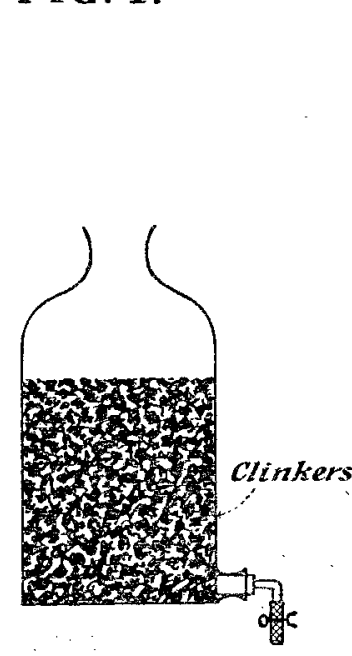

A

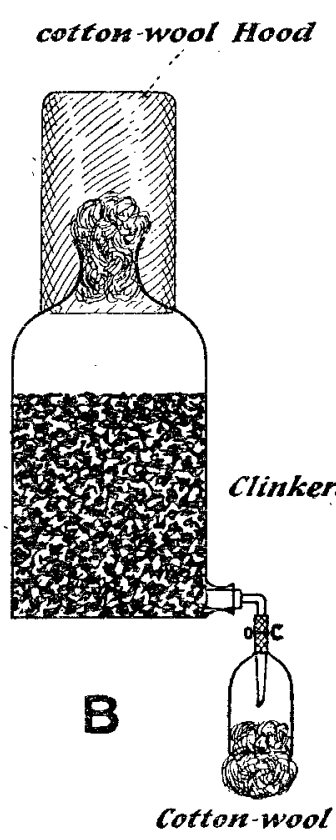

formed by sedimentation or by chemical precipitation, and also that it is very small in amount compared with the total mass of organic matter originally removed by the filter.

At present efforts are being directed to the discovery of means by which the excess of deposit can be got rid of easily ( $c f$. Dibdin's slate bed).

But a filter such as that referred to above is something very different to what was promised in the early days of biological filtration. The bacteria have not risen to the occasion in the way that was anticipated. As a consequence it is not to be wondered at that some authorities are beginning to view their claims to any share of the work with suspicion. One recent writerf

* Massachusetts Report, 1905, p. 368.

† Bretschneider, Städtische Kläranlagen u. ihre Rückstande. Also Gesundheits-Ing. 1905, nr. 15. on the subject, basing his conclusions on the character of colloid solutions* as revealed by the ultramicroscope, states that in his opinion the effect produced in a filter is mainly mechanical; in other words, it is nothing more than a separation or removal of suspended matter by mechanical or mechanico-physical filtration, and that the name "biological filter" is a misnomer, micro-organisms having little to do with the process. If any micro-organismal or enzymic action does take place, it is incidental, and is, as a rule, so insignificant that it may be left out of account. He goes on to say: "I am of opinion that as yet sufficient evidence has not been produced to show that oxidation is brought about by the activity of micro-organisms. I am, indeed, much more

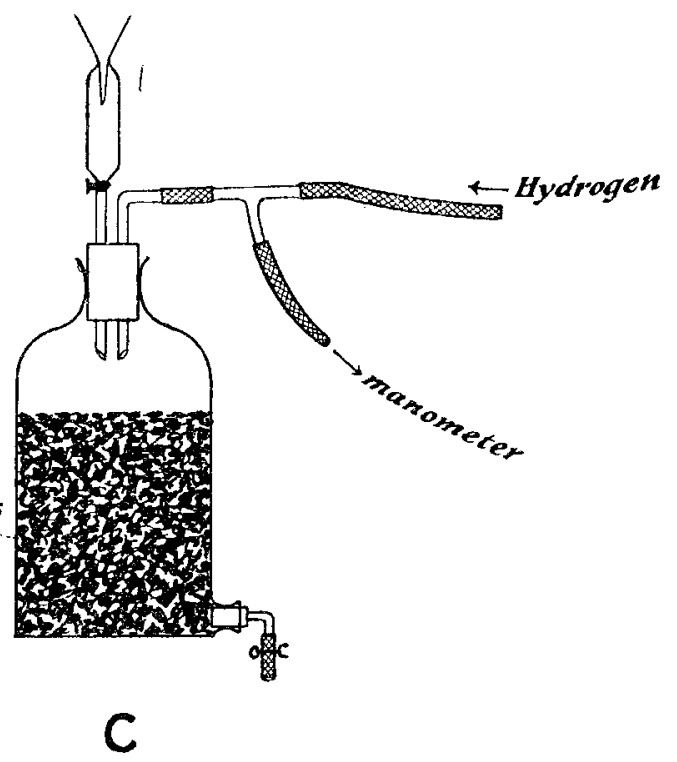

inclined to believe that the air alone is sufficient for this purpose, and that the co-operation of micro-organisms is not essential." Practically this amounts to an acceptance of the first part of Dunbar's theory and rejection of the second. The writer maintains that for the continuance of the process of elimination (or absorption) of colloid matters micro-organisms are not necessary.

A short time ago I had an opportunity of carrying out one or two experiments relative to this matter, the results of which I shall now briefly describe. They were made with the object of ascertaining first whether "mechanical filtration" is sufficient to explain the separation of a colloid from solution as it occurs in a biological filter; secondly, whether it is true

\footnotetext{
* cf. Michaelis, Deutsche Med. Wochenschrifi, I904, nr. 42.
} 
that micro-organisms play no part in bringing about this separation, and finally, whether there is any truth in the view that air alone is sufficient to bring about the various oxidation changes that occur ordinarily in a ripe filter.

The experiments were carried out under conditions which rendered possible the control of the different factors.

Glass bottles of about two litres capacity were used-a size convenient for sterilization and supplying an effluent sufficiently large for purposes of examination. The filtering material selected was hard well-burned clinker- I to $3 \mathrm{~m} . \mathrm{m}$. in diameter-washed, dried, and carefully freed from dust. Of the colloids tried, peptone was found to be the most suitable: it dissolves easily; in solution it is practically uninfluenced by any form of mechanical filtration, e.g., it passes through the pores of a Berkefeld filter without undergoing any appreciable change in concentration; it is easily sterilized; and finally, being a fairly advanced product of the hydrolysis of albumen, it may, in its behaviour in the filter bed, be reasonably compared with some of the products of bacterial action found in sewage.

The strength of solution used ( $0^{\circ} \mathrm{I}$ per cent.) was such as to give a constant value of about 750 for the "oxygen absorbed" (Kubel) expressed in mgms. $\mathrm{KMnO}_{4}$ per litre.

At the commencement of the experiments all three filters were sterilized. Sterile peptone solution was used throughout. The view of the filters (Fig. I) shows that they were exactly alike. They were also handled in identically the same manner, except that during the resting period the air admitted to $B$ was filtered through cotton wool, while that gaining admission to $\mathrm{A}$ was unfiltered. The filter $C$ was supplied with hydrogen gas; it was kept under anærobic conditions.

The filters were filled every third day-except during an interval of one month between the I2th and I3th fillings-and allowed to stand one day full and two days empty. After the $5^{\text {th filling the standing-full period was shortened }}$ to one hour. Considerable difficulty was experienced in keeping $B$ sterile. The first experiment that was made failed on this account-owing to B becoming accidentally infected. The second attempt, however, succeeded, and at the end of $3 \frac{1}{2}$ months the filter and its contents were still quite sterile-gelatine plates inoculated with I c.c. of the effluent and with a fragment of the clinker failing to show any growth.

The chief results are given below in tabular form (Table 3), and also diagrammatically (Fig. 2), the vertical columns representing
FiG. 2.

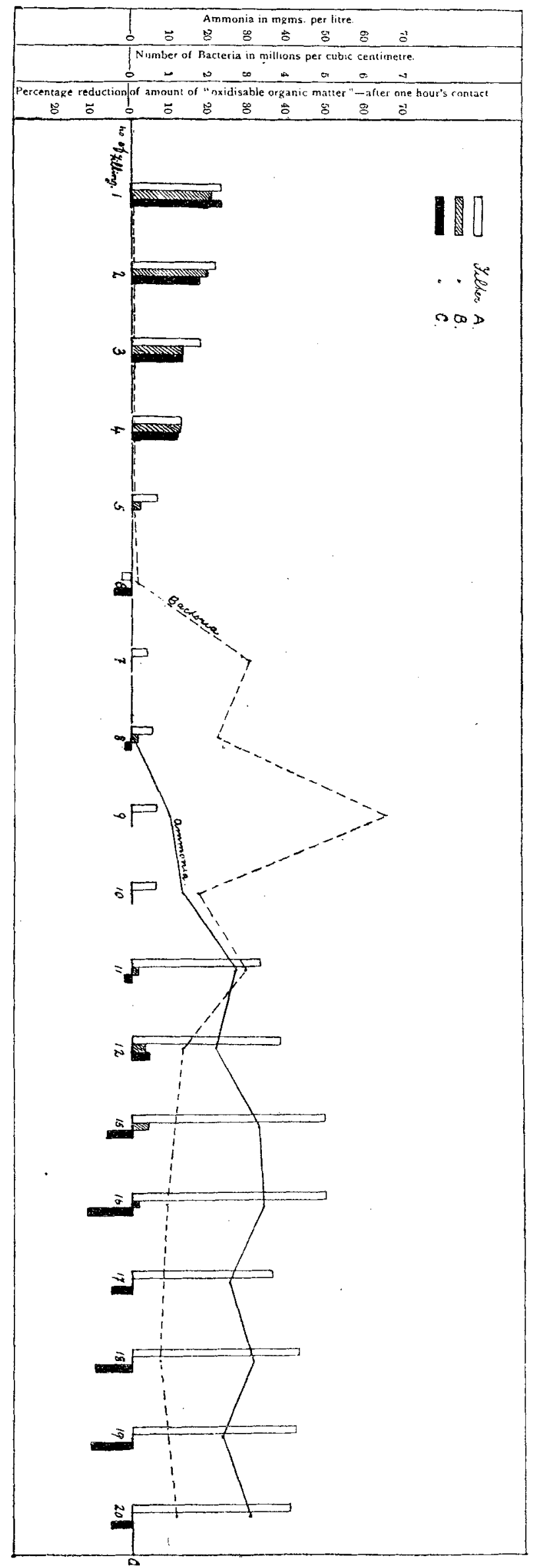


the percentage reduction at each filling of amount of oxidisable organic matter, i.e., peptone and its products effected by one hour's contact in the different filters.

TABLE 3.

Percentage reduction of amount of oxidisable organic matter effected by one hour's contact.

\begin{tabular}{|c|c|c|c|c|}
\hline No. of $F$ & & A. & B. & C. \\
\hline 1 & $\ldots$ & 23 & 208 & 23 \\
\hline 2 & $\ldots$ & 21.5 & $19^{\circ} 6$ & $17^{\circ} 6$ \\
\hline 3 & $\ldots$ & $17^{\circ} 4$ & 13 & I 3 \\
\hline 4 & $\ldots$ & 12.5 & 125 & 12.5 \\
\hline 5 & $\ldots$ & $6 \cdot 26$ & 208 & 0 \\
\hline 6 & $\ldots$ & -2.08 & o & -4.17 \\
\hline 7 & $\ldots$ & 4 & 0 & o \\
\hline 8 & $\ldots$ & $5^{\prime} \mathrm{I}$ & I'7 & -17 \\
\hline 9 & $\ldots$ & $6 . \mathrm{I}$ & 0 & 0 \\
\hline 10 & $\ldots$ & $6 \cdot 1$ & o & 0 \\
\hline I I & $\ldots$ & 327 & 18 & -1.8 \\
\hline 12 & $\ldots$ & 375 & 313 & 469 \\
\hline I 5 & $\ldots$ & 49 & 4.1 & -6.1 \\
\hline 16 & $\ldots$ & $49^{\circ} \mathrm{I}$ & $I^{\prime} 9$ & $-11 \cdot 3$ \\
\hline 17 & $\ldots$ & $35: 6$ & 0 & -5.08 \\
\hline 18 & $\ldots$ & $42^{\prime} 3$ & 0 & -96 \\
\hline 19 & $\ldots$ & $4 I \cdot 6$ & 0 & $-10^{\circ} 4$ \\
\hline 20 & $\ldots$ & 40 & o & $-5 \cdot 4$ \\
\hline
\end{tabular}

From a study of these results it appears that when sterile peptone solution of constant strength is added periodically to a sterile bed of clinker the power of the latter to absorb the peptone gradually diminishes, until finally the peptone flows away in the effluent in the same concentration and in thesame unaltered condition in which it was present in the influent. There is established, in short, a condition of equilibrium which can only be disturbed by some change in the condition of the peptone already absorbed. In the case of $B$ filter no change occurred; as a consequence after the initial power of absorption had once been exhausted the effect of the filter on the solution was nil, and remained so, although air was freely admitted in the resting interval during the whole course of the experiment. It therefore follows that air alone is not sufficient either to maintain the eliminating power of the filter or to initiate oxidation changes in the absorbed peptone. For this other help is necessary.

In $A$, where all the necessary factors were present, we observe a gradual regeneration of the filter and the continued production of a satisfactory effuent. It is true that at first a disappearance of the absorptive power took place, but this was due to the fact that all the filters were sterile at the beginning, and that, though no effort was made to keep A sterile, the number of micro-organisms obtaining access was so small that some time was required to elapse before sufficient were present to cause any appreciable effect. It will be noted that the recovery of absorptive power is almost coincident with the appearance of bacteria in the effluent. (Table 4 and Fig. 2.)

TABLE 4.

FiLTER A.-Samples taken after one hour's contact -

No. of Filling
1
2
3
4
5
6
7
8
9
10
11
12
15
16
17
I8
19
20

No. of Bacteria per c.c. o
Effuent (Gelatine $22^{\circ}$ C.)
0
0
0
0
123
153,200
$3,080,000$
$2,210,000$
$6,530,000$
$1,720,000$
$2,920,000$
$1,340,000$
-
950,000
$=$
720,000
-
$1,130,000$

Ammonia.
Mgms. per litre.
0
0
0
0
0
0
Trace.
Trace.
$9 \cdot 9$
13
26
$21 \cdot 2$
32
$33^{\cdot} \cdot 2$
$24^{\circ} 4$
$3^{\circ} \cdot 8$
23
30

The sharp rise and fall in the bacterial curve seem to point to a process of selection having been at work in the early stages of the life of the filter.

The ammonia curve is also interesting.

To make my conception of the process of purification clearer, I venture an example (see Diagram A).

Let us take a filter-two of the fragments of which are represented in the diagram (Diagram A)-with a total air capacity of I,000 c.c. and a water capacity of 200 c.c. We flood this (dry) filter with $\mathrm{I}, 000$ c.c. of a $O \cdot I$ per cent. peptone solution, and we obtain 8 oo c.c. effluent, showing a reduction in concentration of, say, 20 per cent.-i.e., there are retained in the filter 200 c.c. water and $0.36 \mathrm{gm}$. peptone; in other words, while the concentration of the effluent is 0.08 per cent., that of the "solution" round the fragments of the filter is 0.18 per cent. If at our next filling we used 0.08 per cent. solution no further absorption would take place. Instead of this we again use $0^{\circ} \mathrm{I}$ per cent. solution, and again absorption occurs, and this continues with each filling until finally a condition of equilibrium is established between the peptone in the influent and that already absorbed or deposited in the filter.

With a sterile filter deposition ceases here,. which would not be the case if the process were 
what is ordinarily understood by the word "mechanical,"* or if it were independent of the action of micro-organisms.
Through the action of micro-organisms and their ferments in the presence of oxygen a breaking "down or partial mineralisation of the

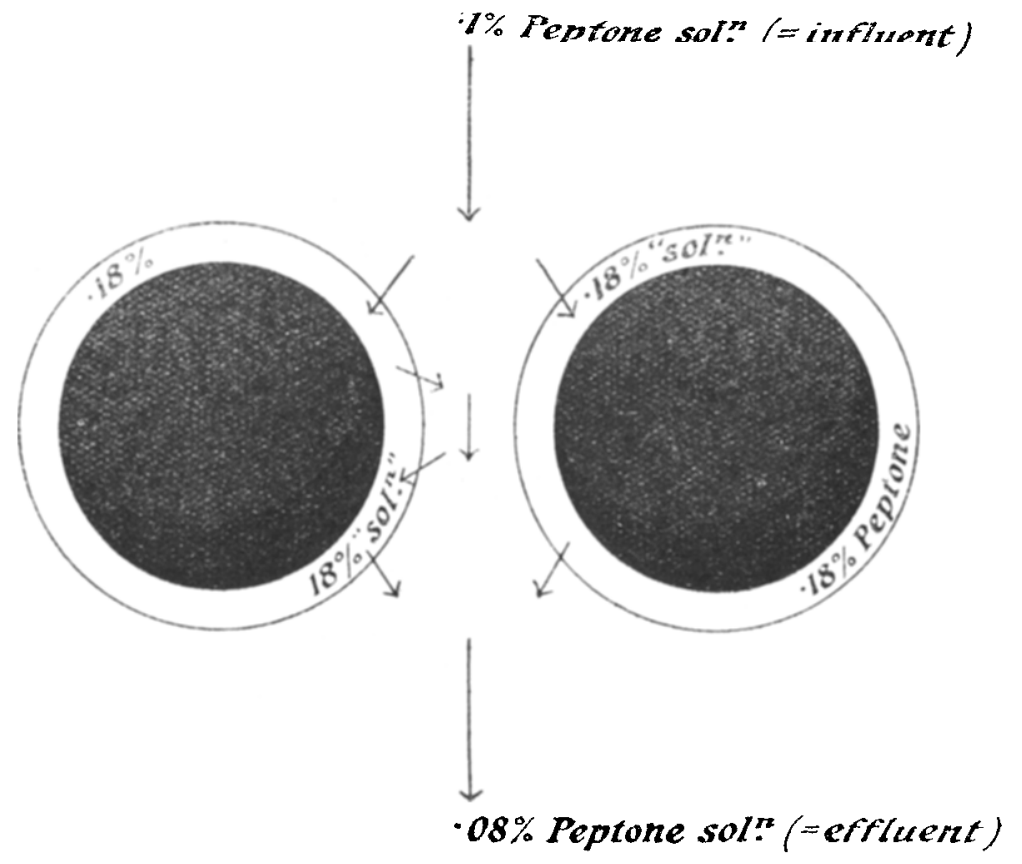

\section{DIAGRAM A}

Diagram $B$ shows the second stage, the stage of regeneration:- peptone occurs. The bodies so formed differ in their properties from the original colloid.

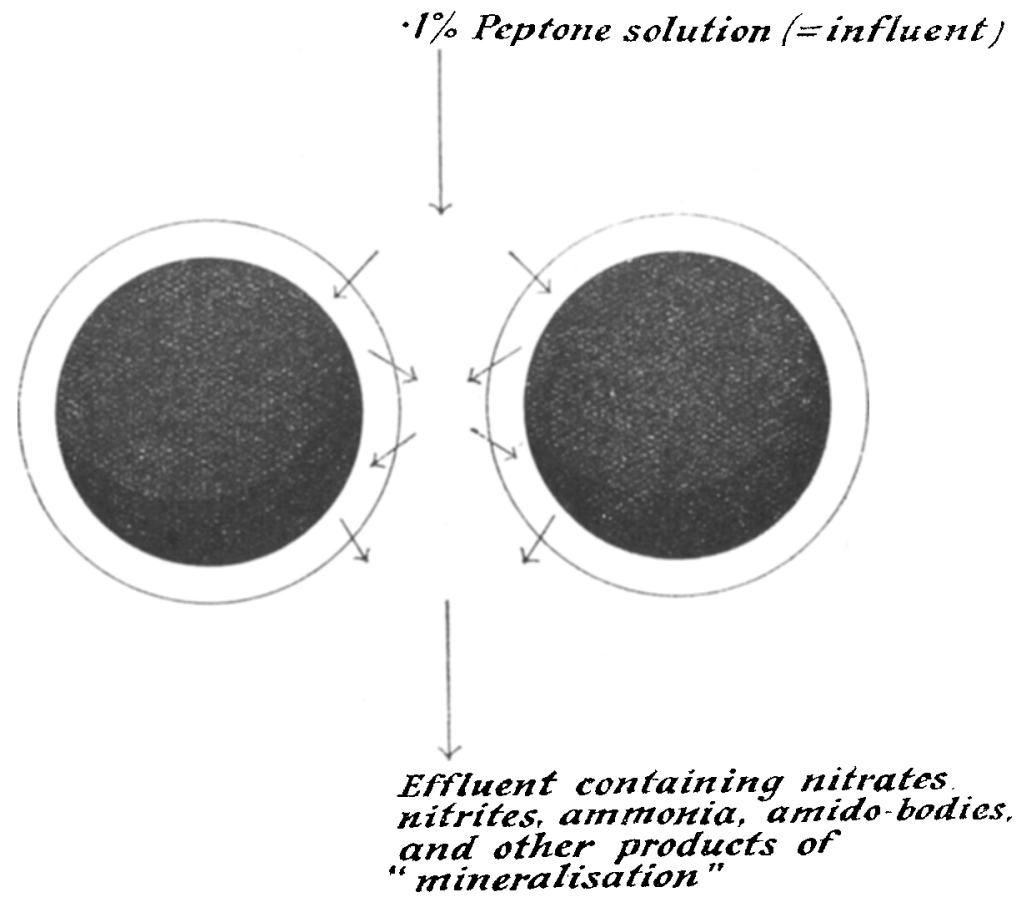

DIAGRAM B

* In this connection $c f$. an interesting paper by Jones and Travis, "Elimination of Suspended Solids and Colloids from Sewage" (Proc. of Inst. of Civil Eng., 1905-6, Paper 3,599), where the bacterial factor, however, does not seem to be given due prominence.

They are simpler, and are either not absorbable at all or less easily absorbable than the mothersubstance. By their formation we get a 
disturbance of equilibrium, which at the next filling results in fresh peptone being absorbed while the nitrates, ammonia, amido-bodies, etc., are eliminated.

The results obtained with Filter $\mathrm{C}$, which was in effect a kind of septic tank, were only such as were to be expected. They show that without oxygen no satisfactory regeneration is possible. The apparent increase in the amount of "oxidisable organic matter" is due partly to the presence of reduced salts of iron (derived from the clinker) which interfered with the test, and partly to the fact that the products of the anærobic fermentation of albumen and of peptone often show a higher value for the oxygen absorbed than the mother-substance.

To sum up the main points of my thesis :-

r. A biological filter eliminates from sewage dissolved putrescible substances almost immediately.

2. This elimination does not directly depend on the presence of micro-organisms.

3. As the substances in question are almost all colloidal it is highly probable that the force at work effecting their elimination is absorption.

4. But absorption does not go on indefinitely. To ensure its continuance a change"mineralisation"-must take place in the absorbed matters.

5. To initiate this change oxygen alone is not sufficient; we require in addition the active presence of micro-organisms (and their ferments).

6. On the other hand, micro-organisms alone are also insufficient, although through them no doubt a partial "mineralisation" does occur. The products of this mineralisation, however, are quite as objectionable as the mother-substances, as evil smelling, and with as great an affinity for oxygen, so that an effluent containing them can no more be considered pure than the original untreated influent.

Tooth-Brush Drill in Schoor.--The regular use of the tooth-brush is practically unknown, and the parents do not appreciate the seriousness of neglecting to keep their children's mouths clean and free from decay. It is useless to preach to parents or children on this matter. The lesson must be driven home by the practical enforcemen $t$ of tooth-cleaning at the school. The daily practice of this just before the commencement of the afternoon session would alone result in a great improvement in the general health.-Annual Report of Dr. R. Ashleigh Glegg, Medisal Officer of Health, Lindsey County Council.

\section{SOME DIFFICULTIES IN THE} CONTROL OF THE MILK SUPPLY.*

By HAROLD KERR, M.D. Edin., D.P.H. Camb., Assistant Medical Officer of Health, Newcastle-on-Tyne.

THE subject I am venturing to address you upon this afternoon is by no means a new one, nor are my remarks likely to include any very novel or original points, but, nevertheless, the matter is one of the highest importance at the present time, and of the very greatest interest to us as sanitarians. Much has been done of late years to educate the public in the ways of healthy living, and much good has resulted; but the process is a slow one, and sometimes a very thankless one, and there are still many directions in which little progress has been made. The milk supply is a striking case in point, for in spite of the great advance in our acquaintanceship with the conditions which affect this almost indispensable commodity, both in its production and in its distribution, and also in our knowledge of the means by which its purity and wholesomeness may be safeguarded, so formidable are the obstacles raised by conservatism, prejudice, ignorance and self-interest, that progress and improvement have been retarded to such an extent as often to nullify the effects of our efforts.

Many local authorities have shown themselves acutely conscious of present defects, and have been for some time actively engaged in endeavouring to remedy them. But unfortunately this activity is confined to certain local centres, principally the larger towns, while the lesser towns and rural districts for the most part continue to maintain an attitude of apathy or even obstruction. So long as this state of affairs exists, individual effort on the part of isolated authorities is of little use to the nation generally, and of not much more to themselves. Little assistance has hitherto been obtained from the Government. Laws, regulations, orders, powers to make bye-laws, and so forth certainly exist, but they are incomplete, fragmentary and indefinite. Further, no disposition has been shown by the central authority to compel local councils to make use, and carry out the terms, of the various enactments; in the parliamentary return of 1907 , showing the districts in which regulations under the Dairies, Cowsheds and Milkshops Order, I885, had been made, it appeared that I2 per cent. of

* Paper read before the Northern Branch of the Society of Medical Officers of Health on April 23rd, rgog. 